\title{
Review
}

\section{DMA data protection day 2015 - In praise of transparency}

Journal of Direct, Data and Digital Marketing Practice (2015) 17, 71-73. doi:10.1057/dddmp.2015.38

\section{Transparency with customers}

\section{ICO can't do it all}

\section{Pointless one euro fines}

Lobbying and trilogue
Now a firmly established annual event in the data protection conference season, the Direct Marketing Association's (DMA) Data Protection Day took place on 27 February. The conference agenda was understandably dominated by the shadow of the new European Union Data Protection Regulation and the difficulties it may present to data users - not to mention regulators - but the focus was very much on how commercial use of data can be maximized, both under the current regime and the forthcoming Regulation through transparent dealings with customers.

The Information Commissioner, Christopher Graham, provided the keynote to the conference. He reminded the audience that he was just entering his last year as Commissioner and emphasized the size of the task ahead in the next 12 months. Graham was clearly delighted to have been handed new powers to prosecute rogue marketers by a change in the legal wording that removes the requirement for the Information Commissioner's Officer (ICO) to prove 'damage or distress' to individuals. Previous prosecutions of 'cowboy' firms had failed because of this hurdle. However, Graham was clear that the new powers would be used with discretion and paid tribute to the support received from the DMA in identifying the culprits — the ICO neither 'knows it all' nor can 'do it all', he said. He was keen on self-regulation (including kitemarks and privacy seals), but admitted that the new powers had meant that the ICO was increasing staffing in enforcement.

On the subject of the Regulation, the Commissioner was as keen as the direct marketing community to get clarity. He felt that the series of European court judgements around data protection issues (including the Google 'right to be forgotten' ruling) were making life increasingly difficult for regulators who then had the job of enforcement. He welcomed the clarity that the Regulation will bring on consent and warned the industry that implied consent should be phased out. He was concerned, however, that the text as it currently stands is over-prescriptive, both for industry and for his office. Graham made it clear that he didn't want to be a 'traffic warden' and couldn't see the merit in levying a one euro fine just to make a point - a view, he admitted, not necessarily shared by his Article 29 Working Party colleagues. In one of the more succinct soundbites of the day, he commented, 'with all the effort, to fine one Euro is stupid. Let me reserve the big stick in the cupboard for those that need a good spanking'.

DMA executive director Chris Combemale talked about how the DMA's lobbying was helping to tone down the Regulation and why 


\section{Guardian's 'golden thread'}

\section{Consumers hate complexity}

\section{Under-pressure consumers}

\section{Prepare for post-Regulation}

sticking to the DMA Code of Practice can help businesses prepare for the future. Echoing the ICO, Combemale explained that the various texts of the Regulation from the European Parliament, European Commission and European Council of Ministers each had good points, but had to be combined during the trilogue process, which is now taking place. DMA sources in Brussels and meetings with key officials had been enlightening. There was believed to be 'headroom' built into each version to allow for the inevitable negotiation process. Combemale also recommended clarity about data use as a brand attribute: 'If you treat customers in a transparent way, you create brand loyalty'.

DMA chair Julia Porter then explained how the Guardian is pushing its data values out to audiences through a 'golden thread' of transparent and straight-talking material. This is part of a programme at the Guardian which relies on revenues derived from data to maintain free access to its journalism. Porter referred to the work done to streamline the DMA Code: 'It was about making data simpler, making it easier and not annoying people'.

But walking the walk of the principles in the Code means becoming 'more grown up' about the value exchange of data for free content, Porter said. Signed-up Guardian users were 20 times more valuable to the newspaper and most likely to be advocates, so gaining their engagement (and data) is vital. The session also allowed Porter to showcase the 'Why your data matters to us' video that has been produced to encourage data sharing from Guardian users. Research conducted before the launch of the video had been enlightening. 'People hate complexity, hate ambiguity. Make it simple and they might be interested' was the message coming back from these sessions, said Porter.

Telefónica's Jonathan Earle presented a forward-thinking session that predicted that brands that use data to make the busy consumer's life easier will win through. He provided a view of the consumer as increasingly under pressure to keep up with the demands of 'always-on' communications. By sharing data across devices and providing technical support, $\mathrm{O} 2$ was winning friends. But all of this had to be done with the customer's knowledge and agreement and under strict security.

Finally, Rosemary Smith from Opt-4 was joined on the DMA 'sofa' by Andy Bridges from Nectar owner, Aimia. They discussed the top ten challenges presented by the likely text of the Data Protection Regulation and how brands should prepare. The overall message of the session was a clear call to action, encouraging delegates to grasp the nettle and start developing systems that are future-proofed to ensure compliance in a postRegulation world.

\section{Ten Biggest challenges}

1. Regulation, not Directive: The 'one-size-fits-all' approach would help companies like Nectar that trade internationally, but Smith and Bridges agreed that the United Kingdom has the toughest job to come into line.

2. Explicit consent - opt-in: Smith challenged the view that opt-in would mean Armageddon. Data Permission Benchmark research was 
showing that transparent wording could achieve up to 65 per cent consent.

3. Specified 'legitimate interests': The 'carve-outs' include the marketing of similar products and services, postal marketing and business-tobusiness, which could be useful as an alternative to opt-in.

4. Documentation - proof of consent: Bridges agreed that most database management systems do not have the required level of granularity to store proof of consent - at the moment, many just record 'yes' or 'no'.

5. Mandatory breach notifications for consumers: If all breaches had to be notified - no matter how insignificant - 'notification fatigue' would soon set in.

6. Privacy impact assessments: Aimia had been using PIAs for a while. A product or service configuration must come first, but the data protection issues need to be addressed at a very early stage as post-rationalisation can be expensive.

7. Restrictions on profiling/use of IP addresses: There was concern that, if we don't get this right, the whole industry could be affected. Explicit consent for all targeting would have a massive impact and we would be back to a scattergun approach.

8. Processor liability: The data processor will share liability for breaches going forward. Bridges advised proper due diligence (Nectar has a 3-month process to find suppliers).

9. Right to erasure, not just removal: While the use of data for suppression had been added back after pressure from the DMA, there were concerns that expectations of full 'erasure' could simply not be met.

10. The appointment of data protection officers (DPOs): We don't know yet whether DPOs will be required, or what will determine their appointment (eg, size of the company or local law), but there is bound to be a significant shortage of qualified people. As a business community with a vested interest in data, we need to work on that. 